\title{
Graphics and Listening Comprehension
}

Valerie Ruhe

How effective are graphics as lecture comprehension supports for low-proficiency ESL listeners? In an experiment conducted with 103 college-level Asian students, a group that heard an audiotape while looking at a page with an organizational graphic performed better on a comprehension test than a control group (no words or graphics provided), whereas the participants in two vocabulary conditions (one with vocabulary from the lecture listed in alphabetical order and the other with vocabulary listed in the order in which the words occurred in the text of the mini-lectures) performed no better than the control group. The findings indicate that the graphics enhanced listening comprehension. Suggestions for using graphics to teach academic listening skills are provided.

Lecture listening skills are generally recognized as important for student success in academic environments (Dunkel, 1991; Mendelsohn, 1994; Powers, 1986). Yet the mental effort required can leave second-language learners overloaded, frustrated, and demoralized (Eastman, 1991; Snow, 1993; Ur, 1984). According to Geddes and White (1978), students often try to focus equally on all parts of a discourse. Unable to attend to everything with equal intensity, they may give up even when they could have grasped the gist of the message. College-bound students expect materials to be relevant to their academic goals and to be pitched at an appropriate level of cognitive maturity.

In their study of Taiwanese college students, Chiang and Dunkel (1992) pointed out that there is no research on the needs of students at lower levels of listening proficiency with respect to the comprehension of lecture discourse. They acknowledged that lectures are extremely difficult for these students and recommended they be given short lectures on familiar topics and written versions of lectures in the prelistening stage.

As an increasing number of Asian students enter college and university programs in North America, there is a growing need to modify content instruction to accommodate the needs of these learners (Brinton, Snow, \& Wesche, 1989; Christianson, 1995). In this article I attempt to explore how graphics can facilitate the second-language lecture comprehension process.

The importance of comprehensible input as a necessary (although insufficient) factor in L2 language learning is well documented in the SLA literature. Krashen (1982) argued that the most effective way to teach a second language is to give learners large amounts of comprehensible input in an environment of low anxiety. Krashen's views on comprehensible input have 
"sparked interest in comprehension-based methodologies and materials" and have led "an increasing number of scholars and practitioners to believe that comprehension processes and strategies need to be taught actively in second language classrooms" (Omaggio-Hadley, 1993, p. 163).

Because meaning is inferred from and understood in context (Brown, 1987; Garrod, 1986), it is not surprising that contextual supports have been shown to benefit L2 listening comprehension (Long, 1990; Mueller, 1980; Murphy, 1987; Rubin, 1994; Voss, 1984). When language is embedded in a context, it is easier for L2 learners to understand (Cummins, 1985). Contextual supports provide clues for recognizing content and overall organization, making logical guesses, testing hypotheses, and making predictions and inferences, all of which are important for comprehension (Long, 1989). Context provides listeners with clues to interpretation, thereby allowing them to cope with input that might otherwise be too difficult.

Contextualizing language is an effective strategy for language teachers because the comprehension process is driven by frames, scripts, or schemata stored in long-term memory (Byrnes, 1984; Carrell, 1985). Freedle and Hale (1979) found that schemata play an important role in L1 reading comprehension, and Carrell $(1983,1985)$ found similar effects on L2 reading. Chiang and Dunkel (1992) have shown that topic familiarity enhances listening comprehension for low-level second-language learners.

Listeners are actively engaged in constructing meaning (Murphy, 1989), a process that relies on both language and contextual clues ( $\mathrm{O}^{\prime}$ Malley, Chamot, \& Kupper, 1989). Using these clues, listeners "chunk" input into meaning-based units that are stored briefly in short-term memory (Call, 1985; O'Malley et al., 1989). This chunking process is vulnerable to disruption by cognitive or attentional capacity overload, L1 interference (Byrnes, 1984; Eastman, 1991), and the greater memory strain posed by L2, as compared with L1, input (Call, 1985). Consequently, input in short-term memory is purged almost immediately to make way for new material (Call, 1985; $\mathrm{O}^{\prime}$ Malley et al., 1989). With no control over what is coming at them, listeners experience anxiety, which in turn impedes comprehension (Mendelsohn, 1994) and maintains their focus of attention at the level of individual words, a strategy used by inefficient listeners (Eastman, 1991; Murphy, 1987; O'Malley et al., 1989; Voss, 1984). This means that new material is neither comprehended nor learned, resulting in the lack of confidence and frustration that has often been observed in listening classes (Eastman, 1991; Snow, 1993; Ur, 1984).

Visually based contextual clues such as pictures and video have been found effective in activating background knowledge and improving comprehension (Baltova, 1994; Brown, 1986; Fitzpatrick, 1989; Krashen, 1982; Levie \& Lentz, 1982; Mueller, 1980; Relan, 1991). Research in L2 listening 
indicates that visuals are most effective with listeners at lower levels of proficiency (Kang, 1995; Mendelsohn, 1994; Mueller, 1980).

One type of visual support includes graphics such as flowcharts, classification trees, webs, and charts. Graphics "depict the organization and structure of key concepts in a content area" (Levie \& Lentz, 1982, p. 215) and are effective in promoting an understanding of L1 content (Alesand rini, 1981; Armbruster \& Anderson, 1984). Because academic language consists of content organized in rhetorical patterns (Mohan, 1986), comprehension of academic language requires the activation of two types of schemata: content (networks of topic-based knowledge) and textual (knowledge of how discourse is organized) (Carrell, 1987; Mendelsohn, 1994). Because the conventions they follow in representing rhetorical patterns are familiar across languages and cultures (Tang, 1993), graphics also promote an understanding of content in a second language (Carrell, 1987; Early \& Tang, 1991; Tang, 1991, 1992). By activating both content and rhetorical schemata simultaneously (Early, 1989), graphics lower the language barrier, reduce shortterm memory load, and help listeners to anticipate, predict, infer, and confirm meanings where a portion of the text has been incompletely understood (Mendelsohn, 1994; O'Malley et al., 1989).

Because a spoken text is not readily visible (Stevick, 1984), graphics may be even more important for listening than reading. Although graphics are commonly used in prelistening activities such as chart completion (Mendelsohn, 1994), graphic fill-in (Omaggio-Hadley, 1993) and text-to-graphic strategies (Ruetten, 1986), this study suggests that graphics do more than activate a schema in the prelistening stage - they can also be used in the listening stage to enhance listening comprehension. This study was carried out in order to determine whether graphics enhance listening comprehension of classroom lectures. If classification trees and process diagrams are used, how can we know that the effect is due to the graphic structure and not the vocabulary labels on the graphic nodes?

\section{Method}

This study used a matched-groups experimental design, which is a more powerful technique than random assignment for balancing out the differences across small groups of participants selected from a heterogeneous population (Shaughnessey \& Zechmeister, 1994). Pairs of participants were matched on the basis of their scores on an instructor-designed listening comprehension pretest. First, the control and graphics group were matched. One year later, the text-order vocabulary group and the alphabetical-order vocabulary group were matched. The former was given content words listed in the order in which they appeared in the text of the mini-lectures, whereas the latter was given the same content words in alphabetical order. The 
vocabulary items given to both groups were identical, that is, the same set of words as on the nodes of the graphics.

I set up four groups in order to ensure that any difference in means between the control and graphics groups was caused by the graphics and not by the vocabulary on the graphic nodes. The two vocabulary groups, then, served as additional control groups. Finally, because of the critical role played by the pretest in a matched-groups design, a correlation was computed between the pretest scores of 27 randomly selected participants and the scores of these same individuals on the listening comprehension section of the Institutional TOEFL.

\section{Participants}

The participants were 103 ESL students at the University College of the Cariboo. Because the ESL college preparatory program focuses on reading and writing, none of the participants was enrolled in any listening courses during the experiment. Furthermore, they had not used any of the materials from the pretest or the test. None of them had received any prior instruction with graphics in their ESL classes at UCC, because instructors in the program were unfamiliar with these techniques. Each participant was assigned to a group. Almost all the participants were young high school graduates, aged 17-21. Two were mature students who had completed a bachelor's degree in their country of origin. Almost all the participants had been in Englishspeaking Canada for less than six months. Volunteers for the two data collection sessions were recruited by instructors who announced the project to their classes. All students who participated in this study volunteered to do so, and all signed a consent sheet informing them clearly of procedures. There were 25 participants in each of the control, graphics, and text-order vocabulary group. The control group consisted of 7 Chinese males, 2 Chinese females, 5 Japanese males, 7 Japanese females, 1 Korean female, 1 Hispanic male, 1 Greek male, and 1 Quebecoise female. The graphics group consisted of 7 Chinese males, 3 Chinese females, 4 Japanese males, 9 Japanese females, 1 Korean male, and 1 Korean female. The text-order vocabulary group consisted of 3 Chinese males, 4 Chinese females, 6 Japanese males, 11 Japanese females, and 1 Korean male. The alphabetical-order vocabulary group consisted of 28 participants: 4 Chinese males, 4 Chinese females, 6 Japanese males, 9 Japanese females, 2 Korean females, 1 Korean male, 1 Hispanic male, and 1 Hindi female.

\section{Materials}

The test consisted of four mini-lectures from English on Campus (James, Whitley, \& Bode, 1990) and Interactive Listening on Campus (James, 1992). All materials were used with the permission of Heinle and Heinle. The pretest 
consisted of 20 questions concerning three mini-lectures developed by the researcher in a format and length similar to the test materials.

The four test mini-lectures dealt with the following topics: stress $3: 10$ minutes, 479 words; 154 words per minute) bridges ( $3: 17$ minutes, 515 words; $162 \mathrm{wpm}$ ), the food chain ( 2 minutes, 262 words; $132 \mathrm{wpm}$ ) and recycling (1:50 minutes, 279 words; $185 \mathrm{wpm}$ ). These lectures were chosen because they dealt with two content areas believed to be generally familiar (stress and the food chain) and two likely to be unfamiliar (types of bridges and recycling waste water). In each of these familiar/unfamiliar categories, two lectures were chosen to represent both levels of Mohan's (1986) theory of knowledge structures - concrete (conceptually easy) and abstract (conceptually difficult). In the Familiar category, for example, the lecture on stress was chosen because it was based on classification, an abstract structure, whereas the food chain lecture was chosen because it reflected process, a "concrete" structure.

The graphics, alphabetical-order, and text-order word lists were constructed by the researcher (Appendix A). Participants in the control group were given a combine-the-dots exercise to keep them occupied. The test questions were written to reflect an even distribution of comprehension categories based on Lund (1990): main idea, supporting information, and details/identification.

\section{Procedure}

The data for the control and graphics groups were collected in the winter of 1994, and the data for the two vocabulary groups in the winter of 1995. During each session, all four groups performed under similar conditions, which differed only in the task supports provided with the comprehension questions.

In the winter of 1994, I piloted testing procedures and test questions with an intermediate-level ESL class. This helped me to revise the questions and refine the instructions. After the pretest scores were collected for the control and graphics group, 27 participants were chosen at random to write the listening comprehension section of the Institutional TOEFL, and the Pearson correlation between their TOEFL scores and their scores on the pretest used in this study was computed. Two researchers then worked independently to code the test questions into Lund's (1990) categories; there was $85 \%$ agreement on the coding of the questions. The remaining cases were resolved through discussion, although in a few instances, questions were rewritten.

To minimize the effects of test practice, the test was conducted one month after the pretest. The test administrators and participants were informed that the purpose of the experiment was to assess the effects of task supports on listening comprehension, but they were not told specifically what these supports were. During the data collection sessions, participants were as- 
sembled in the same room. Before each mini-lecture was played, participants were given one minute to study their respective task supports. All participants were then instructed to listen to the lectures, which were played twice, as recommended by Lund (1991), and to take notes either underneath or to the right of the task supports. All participants were given three minutes to answer the 10 questions for each lecture and were allowed to look at their notes while they answered the questions. To limit fatigue, a 10-minute break was given between the second and third lectures. The entire procedure took about 50 minutes. The same procedure was followed for the two vocabulary groups one year later.

Two researchers worked independently to code each of the 40 test questions into one of two groups: (a) questions for which the graphics provided some help, and (b) questions for which the graphics provided no help (called the non-graphic questions). A repeated measures analysis of variance was done on both question sets. A Cramer's $V$ test was also performed to determine the extent to which differences in task means were caused by some tasks being more difficult than others.

Finally, two researchers independently coded the participants' lecture notes for each task into categories based on the extent of their deliberate linkage to the graphics or word lists. Each task was coded, giving a total of 100 tasks for each of the control, graphics, and text-order groups and 112 for the alphabetical-order group. There were four categories: (a) Poor Notes (no notes, notes of 12 words or less, and native language notes); (b) Notes Minus Connection (notes below or beside the graphic or vocabulary list but with no lines or connections to them); (c) Notes Plus Connection (notes below, beside, or all over the graphic or vocabulary list connected with lines, circles, or arrows or in close proximity to them; and (d) Notes and Student Graphic (notes including graphics that the students had drawn themselves). Interrater reliability on the 112 coded items was $84 \%$. (The raters discussed their reasons for disagreement on the disputed items to reach final agreement.)

\section{Results}

\section{Pretest}

The pretest grand means were $12.4(62 \%)$ for the control group, $12.3(61.5 \%)$ for the graphics group, $12.3(61.5 \%)$ for the text-order group, and $11.9(59.5 \%)$ for the alphabetical-order group. Pretest scores were normally distributed with a standard deviation of $13 \%$ for all groups. A univariate $F$-test indicated that these means were equivalent; $F(1,99)=.09, p>.96$. As expected, total scores on the pretests and the Institutional TOEFL were positively correlated $(r(26)=.50, p<.01)$. 
Test

There were considerable differences in cell means among the four groups (see Table 1). As Table 1 shows, the graphics group scored $16 \%$ higher than the control group. Relative differences between the control group and each of the two vocabulary groups were minimal, with the exception of task 3 , where both vocabulary groups did better than the control group.

\section{Analysis}

An overall multivariate $F$-test indicated significant differences among the four groups, $F(12,254)=2.66, p<.005$. BMDP $4 \mathrm{v}$ planned multiple and univariate comparisons (Dixson, 1992) were carried out to show exactly where the differences were. F-tests based on mean scores for all four tasks show significant differences (see Table 2).

Univariate $F$ s (i.e., separate $F$-tests for each task) were significant on all comparisons $(p<.05)$ except on the comparison between the control and text-order vocabulary groups, where there were no differences on tasks 1,2, and 4 ( $p$ values from .4 to .8 ), but a difference on task $3,(p<.05)$. There were no significant differences among any of the no-graph means (see Table 3 ). Univariate $F$ s yielded $p$-values from .22 to .75 .

Next, a Cramer's $V$ test, based on the number of correct and incorrect responses across all 103 participants was carried out to determine whether the four tasks were of equal difficulty. It suggested that tasks 2,3, and 4 were

Table 1

Graphics-Related Questions: Group Task Means

\begin{tabular}{|c|c|c|c|c|c|}
\hline \multirow{3}{*}{ Task } & \multicolumn{4}{|c|}{ Group Task Means (\%) and Standard Deviations } & \multirow{3}{*}{$\begin{array}{l}\text { Grand } \\
\text { Means }\end{array}$} \\
\hline & Stress & Bridges & $\begin{array}{l}\text { Food } \\
\text { Chain }\end{array}$ & Recycling & \\
\hline & 1 & 2 & 3 & 4 & \\
\hline \multicolumn{6}{|c|}{ Control } \\
\hline M & 63 & 58 & 52 & 56 & 57 \\
\hline SD & 21 & 22 & 22 & 18 & 21 \\
\hline \multicolumn{6}{|c|}{ Graphics } \\
\hline M & 83 & 74 & 68 & 69 & 73 \\
\hline SD & 21 & 17 & 12 & 16 & 16 \\
\hline \multicolumn{6}{|c|}{ Alphabetical order } \\
\hline M & 65 & 59 & 60 & 50 & 60 \\
\hline SD & 18 & 16 & 19 & 19 & 18 \\
\hline \multicolumn{6}{|c|}{ Text order } \\
\hline $\mathrm{M}$ & 68 & 59 & 64 & 55 & 61 \\
\hline SD & 25 & 19 & 16 & 18 & 19 \\
\hline
\end{tabular}


Table 2

F-Scores

\begin{tabular}{lrrr}
\hline $\begin{array}{l}\text { Source } \\
\text { Control, Graphic, Alphabet, text order }\end{array}$ & $d f$ & $F$ & $p$ \\
\hline$C \times G \times V(a) \times V(t)$ & $(12,254)$ & 2.66 & $<.05$ \\
$C \times G$ & $(4,96)$ & 4.83 & $<.05$ \\
$C \times V(a)$ & $(4,96)$ & .79 & $n s$ \\
$C \times V(t)$ & $(4,96)$ & 2.04 & $n s$ \\
$G \times V(a)$ & $(4,96)$ & 4.18 & $<.05$ \\
$G \times V(t)$ & $(4,96)$ & 4.49 & $<.05$ \\
\hline
\end{tabular}

of equivalent difficulty, chi square (2) $=1.676, p>.40$, Cramer's $V=.03$ (percent correct responses were $62.3,61.2$, and 59.2 respectively). However, task 1 was somewhat easier at $69.6 \%$ correct (chi square $(3)=18.177, p<.001$, Cramer's $V=.075)$, a pattern that held for all four groups. As the value of Cramer's $V$ indicates, the effect was small, and the slightly higher average score for task 1 did not produce a ceiling effect that masked group differences.

\section{Notetaking Findings}

Interestingly, several individuals in the non-graphics groups drew graphics (see Table 4). In many instances, on the other hand, the graphics group wrote notes directly on top of the graphics provided, despite written instructions to write below or beside them.

\section{Discussion}

Because the mean scores of the vocabulary groups did not differ significantly from the mean scores for the control group, we can conclude that it was the graphics, and not the vocabulary labels on the graphic nodes, that were responsible for the enhanced comprehension in the graphics group.

As shown in Table 2, the no-graph results provide additional confirmation that the four groups were evenly matched for listening proficiency.

Table 3

Non-Graphic Question Sets: Group Means (Tasks 1-4) and Standard Deviations

\begin{tabular}{lll}
\hline Group & $M$ & $S D$ \\
\hline Control & 57 & 22 \\
Graphic & 59 & 21 \\
Vocabulary (a) & 52 & 20 \\
Vocabulary $(t)$ & 59 & 18 \\
Grand Mean & 57 & 20 \\
\hline
\end{tabular}


Table 4

Student Lecture Notes With/Without Connections to Task Supports $(N=100)$

\begin{tabular}{llccc}
\hline Group & Poor & -Connection & +Connection & Own Graphic \\
\hline Control & 13 & 69 & 0 & 18 \\
Graphic & 19 & 24 & 54 & 3 \\
Alphabetic & 10 & 33 & 42 & 15 \\
Text order & 13 & 31 & 43 & 13 \\
\hline
\end{tabular}

Consequently, we can conclude that differences in group means were not a result of mismatched groups. The close similarities between the grand means of the control group and the two vocabulary groups indicate that the better performance of the graphics group was due to the diagrammatic features in combination with the vocabulary labels and not a result of the vocabulary alone.

The results of Cramer's $V$ indicate that the tasks were of equivalent difficulty, with task 1 being only slightly, but not significantly, easier. These findings suggest that any effects of viewing comprehension (which, according to Reinking, 1986, may be impossible to disentangle in any research on the effects of graphics on comprehension) were distributed evenly across tasks 1-3. Because the questions on task 4, however, could not be answered from the graphic, the similar cell means across task conditions and the results of Cramer's $V$ lead to the conclusion that the graphics enhanced listening comprehension.

How exactly do graphics influence the listening comprehension process? First, graphics may activate content and rhetorical schemata and provide an illustrative equivalent of the language of rhetorical patterns, that is, a readily visible framework or conceptual guide that reveals how the content words are related.

By "revealing" the organizational patterns, graphics provide a strategy for dealing with the problem identified by Clerehan (1995) that many L2 students miss the rhetorical/logical structure words of lecture discourse, a problem that is frequently evident in their notes. One of my Japanese students reported that when he listened to lectures in English, he had to hold the beginning of a sentence in short-term memory, listen until the end of the sentence, and then work backward to decode the meaning; he felt that this strategy was caused by his reliance on Japanese word order. This process of working backward to process a noncognate language sounds so mentally taxing that it is easy to imagine how rhetorical patterns could become lost. By guiding the transformation of input into meaning, graphics may also help to reduce anxiety, fear of failure, and frustration, thereby creating an affective climate more conducive to listening comprehension. 
A third way in which graphics facilitate comprehension is by focusing listeners' attention on main ideas and rhetorical patterns, thereby subverting the inefficient strategy of focusing on individual words (Eastman, 1991; Mendelsohn, 1994; Murphy, 1987). Moreover, graphics do not require students to process more text, as would be the case with written notes.

In addition, graphics may affect the way in which auditory text is processed; more specifically, graphics appear to stimulate a process of cognitive matching. Fisher (1984) claimed that when listeners process visual and linguistic information, they are engaged in a process of cognitively matching the information in the visual channel with the information in the auditory channel. In addition, they use the former to fill in any shortcomings in their understanding of the latter. This matching process can help learners to anticipate, predict, integrate, fill in, confirm, and infer meaning (Early, 1989; Mendelsohn, 1994; O'Malley, et al., 1989; Oxford, 1991). According to Severin (1968), cognitive matching can lead to greater overall learning.

The notetaking results in this study suggest that the participants were engaged in cognitive matching of the information in the audio and visual channels. Eighteen out of 25 participants in the graphics group wrote their lecture notes for one or more tasks all over the graphics. The notes on the fourth graphic provide the most solid evidence of this effect. Almost all the participants wrote the terms industry or protect the environment at the top of their notes. One student wrote "no air" and another wrote "doesn't have air" next to anaerobic on the graphic, taking the definition from the audio text and writing it next to the unfamiliar term anaerobic. Because these words were present only in the audio text, their appearance on the graphic as notes indicates that the participants were matching information from the two channels as they were listening. Their behavior provides a striking contrast to observations in other studies that learners tend to ignore graphics (Levie \& Lentz, 1982; Tang, 1991; Voss, 1984). This may be because the participants in this study were functioning in a perceived test situation (although they were told that it was not a test).

Taking notes on the graphics also allows listeners to capture or pin down a mass of content words and to attach these words to a readily visible framework. In this way, disconnected words are connected into webs of meaning. By anchoring content words onto a visible structure that reflects the hard-to-grasp rhetorical patterns, a listener can store input in short-term memory.

The literature on listening comprehension strategies makes no mention of the teaching strategy of recommending to students that they write their lecture notes on a graphic. Moreover, the participants in this study did not learn this strategy in any of their ESL courses at the University College of the Cariboo, which at the time of this study, offered no courses or instruction based on Mohan's (1986) language and content approach. The participants 
appeared to have transferred this strategy from content classes in their countries of origin.

The results on task 4 raise the issue of how the design of a graphic can affect listening comprehension. Robinson and Schraw (1994) stated that although graphics are effective in helping learners grasp the big picture, numerous problems can interfere with the process, including insufficient background knowledge and incoherence in the text itself. These kinds of problems, which Robinson and Schraw observed in L1 reading, may have a significant impact on L2 listening.

In this study, the fourth graphic contains a design flaw: the first step in the process, which is buried as an afterthought in the middle of the auditory text, is omitted completely from the diagram. Two more potential sources of confusion are that the nodes were drawn asymmetrically and that one label is ambiguous-plant in sewage plant is interpreted by at least one subject to refer to a living organism instead of a factory.

When presented with the fourth graphic, however, some students wrote notes that appear to make the diagram fit their understanding of the "proper" ordering of ideas. Many drew arrows back to the beginning or extended the diagram with their own lines. Three of them wrote "starting point" at the top, indicating their understanding that the diagram represented a process. Two later complained to the researcher that the graphic was wrong-one said it should have been a circle and the other was disturbed by its asymmetry. Three students extended one of the steps in the fourth diagram with arrows and key words. Others extended the graphic to fit with their understanding of the complete sequence of events.

These findings provide evidence that the participants were actively engaged in linking the auditory text with the graphic. Rather than distracting them from the auditory text (MacWilliam, 1986), the fourth graphic, perhaps because of the anomalies it contained, pushed the participants to reconcile the information in the audio channel with that of the visual channel.

It is important to note that, even though the fourth graphic was not ideal, the graphics group still managed to do significantly better on task 4 than either the control group or the two vocabulary groups. Given the overall results, it seems safe to conclude that as long as the graphic is accurate overall, minor design flaws do not undo the beneficial effects.

To maximize their effects with intermediate-level ESL students, however, graphics should be designed carefully (Early, 1989; Early \& Tang, 1991). As students become more confident with their language skills, graphics with errors, flaws, or omissions may even be deliberately presented as a means of forcing the cognitive matching process or teaching critical thinking skills (Reinking, 1986).

The results of this study support both Call's (1985) contention that vocabulary lists do not assist short-term memory and Mendelsohn's (1994) asser- 
tion that vocabulary lists are not effective in activating background knowledge. The vocabulary lists in this study did not appear to stimulate a connection with background knowledge. This study suggests that whatever beneficial effects vocabulary lists may have in controlling phonemic mishearings (Rost, 1990), these benefits appear to be insufficient for enhancing comprehension. The participants' notes on the vocabulary lists are revealing in this respect. Many wrote their notes next to the relevant lexical items and drew lines, circles, and arrows to connect the vocabulary. Several constructed their own classification trees or process diagrams, whereas others circled groups of words, associating them in a semantic or conceptual field. Their notes suggest that the vocabulary lists were conceptually incomplete; the students appeared to apply a conceptual organization to the text. Their behavior provides evidence of "a process which relates directly to ... activating prior knowledge when listening" (Mendelsohn, 1994, p. 30).

Task 3 was the only task in which both vocabulary groups did better than the control group. The mean score was $52 \%$ for the control group, but $64 \%$ for the text-order group, and $60 \%$ for the alphabetical-order group, which univariate $F$ s reveal to be significantly different at the .05 level (see Table 1). The word list appears to be complete enough to allow the participants to infer that the lecture deals with the food chain. It is also a coincidence that the order of words in the alphabetical-order group reflects most of the correct conceptual order, which may help explain the high performance on this task (which, however, is not as high as that of the text-order group). The topic of the food chain, subsumed under Anderson's (1985) natural categories, may also have had a higher degree of familiarity than the other topics. With both of these conditions in effect, the vocabulary lists for task 3 presumably allowed the participants to infer the appropriate schema and shifted their attention away from determining the meanings of individual words $\left(\mathrm{O}^{\prime}\right.$ Malley et al., 1989). The participants' notes all over the vocabulary lists provide further support for the hypothesis that "comprehension is always aimed at recovering significance even under circumstances where the listener has to 'conjure up' a context in which to do this" (Garrod, 1986, p. 236). The results demonstrate that vocabulary lists can help when the vocabulary is complete enough to help students to infer the relevant schema.

The following activities illustrate how graphics can be used to teach listening comprehension. As a prelistening activity, an instructor could make explicit connections between language markers and a graphic. The instructor could tell the students that as they listen, they are to look at the graphic and check off the words on a list as they hear them. A cloze exercise could also be used to practice recognition of rhetorical patterns.

The instructor could use a lecture transcript to highlight the language of rhetorical patterns corresponding to the appropriate nodes on the graphic, and could then cover part of the graphic and ask questions to elicit a descrip- 
tion of the covered area (Tang, 1993). This could be followed by an information gap activity in which one student describes a graphic verbally while a partner draws a corresponding graphic.

When used in these ways, graphics function as teaching tools. They provide a mechanism for helping students recognize the small but difficult structure words that are hard to comprehend when the input consists of fleeting auditory text. As students become more confident, graphics can be designed with less information and eventually withdrawn.

Mendelsohn (1994) stated that it is precisely because extralinguistic cues give away some of the meaning that a great deal can be learned from their inclusion. The advantages of video and closed captions are supported by research (MacWilliam, 1986) and are here to stay precisely because they provide clues to meaning around which listening comprehension strategies can be built (Mendelsohn, 1994).

\section{Conclusion}

This study suggests that graphics-based strategies can be effective in improving listening comprehension. The availability of graphics may stimulate a process of cognitive matching of the visual with the audio information. Vocabulary lists do not appear to enhance comprehension unless the words are listed in ways that allow listeners to infer the appropriate schema. Finally, various graphics-based strategies can be designed to support the teaching of lecture comprehension. A limitation of this study is that only one level of listening proficiency was examined and only four mini-lectures were used. Because of the difficulty of testing schemata-based comprehension, the quantitative results should be interpreted with caution. Although the results on task 4 suggest that graphics enhance listening comprehension, the notetaking results provide evidence that graphics influence the processing of auditory text. Further research is needed to determine how graphics can be used to stimulate cognitive matching and how these types of interventions affect the listening comprehension process.

\section{Acknowledgments}

I would like to thank Adrian Kershaw, Charles Mossop, Susan Safford, Steve Schere, Gerry Hewitt, Christie Cole, Margaret Huff, Saphira Coutts, Stephanie Shimmin, Johanna Walters, RobertMacKinnon, the 103 student participants, and especially William Roberts, all of whom are with the University College of the Cariboo in Kamloops. I would also like to thank Gloria Tang at UBC and Lisa Winkler, Permissions Editor at Heinle and Heinle.

\section{The Author}

Valerie Ruhe teaches English for Academic Purposes at the University College of the Cariboo in Kamloops, BC. She has 20 years of ESL teaching experience and is interested in listening comprehension and computer-assisted instruction. 


\section{References}

Alesandrini, K.L. (1981). Pictorial-verbal and analytic-holistic learning strategies in science learning. Journal of Educational Psychology, 73, 358-368.

Anderson, J.R. (1985). Cognitive psychology and its implications (2nd ed.). New York: Freeman.

Armbruster, B.B., \& Anderson, T.H. (1984). Mapping: Representing informative text diagramatically. In C.D. Holley \& H.F. Dansereau (Eds.), Spatial learning strategies (pp. 189-209). New York: Academic Press.

Baltova, I. (1994). The impact of video on the comprehension skills of core French students. Canadian Modern Language Review, 50, 507-521.

Brinton, D.M., Snow, M.A., \& Wesche, M.B. (1989). Content-based second language instruction. Boston, MA: Heinle \& Heinle.

Brown, G. (1986). Investigating listening comprehension in context. Applied Linguistics, 7, 284-302.

Brown, J. (1987). Listening-Ubiquitous yet obscure. Journal of the International Listening Association, 1, 3-14.

Byrnes, H. (1984). The role of listening comprehension: A theoretical base. Foreign Language Annals, 17, 317-329.

Call, M.E. (1985). Auditory short-term memory, listening comprehension and the input hypothesis. TESOL Quarterly, 19, 765-781.

Carrell, P.L. (1983). Background knowledge in second language comprehension. Language Learning and Communication, 2, 25-34.

Carrell, P.L. (1985). Facilitating ESL reading by teaching text structure. TESOL Quarterly, 19, 727-752.

Carrell, P.L. (1987). Content and formal schemata in ESL reading. TESOL Quarterly, 21, 461-482.

Chiang, C.S., \& Dunkel, P. (1992). The effect of speech modification, prior knowledge, and listening proficiency on EFL lecture learning. TESOL Quarterly, 26, 345-374.

Christianson, K. (1995). Affective barriers, schema theory and teaching in a foreign language. [Online]. (1995, May). Available: http:/ /www.u-aizu.ac.jp/kiel/.

Clerehan, R. (1995). Taking it down: Notetaking practices of L1 and L2 students. ESP Journal, $14,137-155$.

Cummins, J. (1985). Bilingualism and special education: Issues in assessment and pedagogy. San Diego, CA: College Hill Press.

Dixson, W.J. (Ed.). (1992). BMDP statistical software manual. Los Angeles, CA: University of California Press.

Dunkel, P. (1991). Listening in the native and second/foreign language: Towards an integration of research and practice. TESOL Quarterly, 25, 431-457.

Early, M. (1989). Using key visuals to aid ESL students' comprehension of content classroom texts. Reading Canada Lecture, 7, 202-212.

Early, M., \& Tang, G.M. (1991). Helping ESL students cope with content-based texts. TESL Canada Journal, 8(2), 34-44.

Eastman, J.K. (1991). Learning to listen and comprehend: The beginning stages. System, 19, 179-187.

Fisher, E. (1984). Television and language development. Journal of Educational Television, 10, 85-90.

Fitzpatrick, D. (1989). The effects of visual format and mode of presentation on nonnative speaker comprehension of verbal information. Unpublished master's thesis, University of British Columbia.

Freedle, R.O., \& Hale, G. (1979). Acquisition of new comprehension schemata for expository prose by transfer of narrative schema. In R.O. Freedle (Ed.), New directions in discourse processing (pp. 121-135). Norwood, NJ: Ablex.

Garrod, S. (1986). Language comprehension in context: A psychological perspective. Applied Linguistics, 7, 226-238. 
Geddes, M., \& White, R.(1978). The use of semi-scripted simulated authentic speech in listening comprehension. Audiovisual Language Journal, 16, 137-145.

James, G. (1992). Interactive listening on campus. Boston, MA: Heinle \& Heinle.

James, G., Whitley, C. \& Bode, S. (1990). English on campus: A listening sampler. Belmont, CA: Wadsworth.

Kang, S. (1995). The effects of a context-embedded approach to second-language vocabulary learning. System, 23, 143-155.

Krashen, S. (1982). Principles and practices in second language acquisition. New York: Pergamon. Levie, W.H., \& Lentz, R. (1982). Effects of text illustrations: A review of research. Educational Communication and Technology Journal, 30, 195-232.

Long, D. (1989). Second language listening comprehension: A schema-theoretic perspective. Modern Language Journal, 73, 32-40.

Long, D. (1990). What you don't know can't help you: An exploratory study of background knowledge and second language listening comprehension. Studies in Second Language Acquisition, 12, 65-80.

Lund, R.J. (1990). A taxonomy for teaching second language listening. Foreign Language Annals $23,105-115$.

Lund, R.J. (1991). A comparison of second language listening and reading comprehension. Modern Language Journal, 75, 196-204.

MacWilliam, I. (1986). Video and language comprehension. ELT Journal, 40, 131-135.

Mendelsohn, D.J. (1994). Learning to listen. San Diego, CA: Dominie Press.

Mohan, B.A. (1986). Language and content. Reading, MA: Addison-Wesley.

Mueller, G.A. (1980). Visual contextual cues and listening comprehension: An experiment. Modern Language Journal, 64, 335-340.

Murphy, J.M. (1987). The listening strategies of English as a second language college students. Research and Teaching in Developmental Education, 4, 27-46.

Murphy, J.M. (1989). Listening in a second language: Hermeneutics and inner speech. TESL Canada Journal, 6(2), 27-44.

Omaggio-Hadley, A. (1993). Teaching language in context (2nd ed.). Boston, MA: Heinle \& Heinle.

O'Malley, M.J., Chamot, A., \& Kupper, L. (1989). Listening comprehension strategies in second language acquisition. Applied Linguistics, 10, 418-436.

Oxford, R.L. (1991). Research update on teaching L2 listening. System, 21, 205-211.

Powers, D.E. (1986). Academic demands related to listening skills. In A. Hughes \& D. Porter (Eds.), Language testing (pp. 1-34). Gateshead, UK: Paradigm Print.

Reinking, D. (1986). Integrating graphic aids into content area instruction: The graphic information lesson. Joumal of Reading, 30, 146-151.

Relan, A. (1991). Effectiveness of a visual comparative advance organizer in teaching biology. Research in Science and Technological Education, 9, 213-221.

Robinson, D.H., \& Schraw, G. (1994). Computational efficiency through visual argument: Do graphics communicate relations in text too effectively? Contemporary Educational Psychology, 19, 399-415.

Rost, M. (1990). Listening in language learning. New York: Longman.

Rubin, J. (1994). A review of second language listening comprehension research. Modern Language Journal, 78, 199-221.

Ruetten, M. (1986). Comprehending academic lectures. New York: Maxwell McMillan.

Severin, W. (1968). Cue summation in multiple channel communication. Madison, WI: University of Wisconsin.

Shaughnessey, J.J., \& Zechmeister, E.B. (1994). Research methods in psychology (3rd ed.). Toronto, ON: McGraw-Hill.

Stevick, E. (1984). Similarities and differences between oral and written comprehension: An imagist view. Foreign Language Annals, 17, 281-83.

Snow, M. (1993). University lectures? We're ready! TESL Reporter, 26(2), 56-60. 
Tang, G.M. (1991). The role and value of graphic representation of knowledge structures in ESL student learning: An ethnographic study. TESL Canada Journal, 9, 29-38.

Tang, G.M. (1992). The effect of graphic representation of knowledge structures on ESL reading comprehension. Studies in Second Language Acquisition, 14, 177-195.

Tang, G.M. (1993). Teaching content knowledge and ESOL in multicultural classrooms. TESOL Journal, 8-12.

Ur, P. (1984). Teaching listening comprehension. New York: Cambridge University Press.

Voss, B. (1984). Slips of the ear: Investigations into speech perception behaviour of German speakers of English. Tubingen: Narr.

\section{Appendix A: Graphics, Tasks 1-4}

\section{Lecture 1}

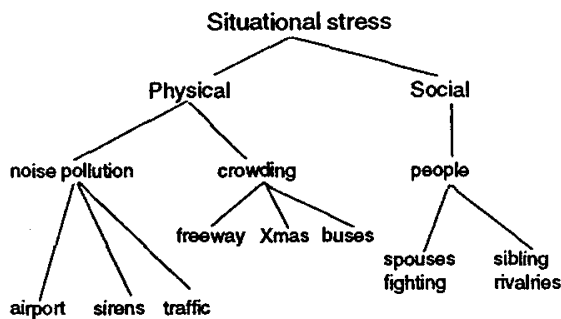

Lecture 3

\section{Lecture 2}

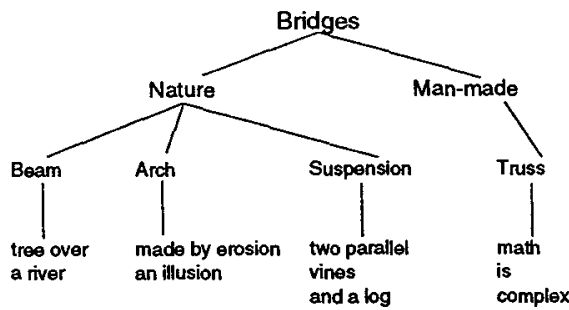

Lecture 4

Recycling waste water

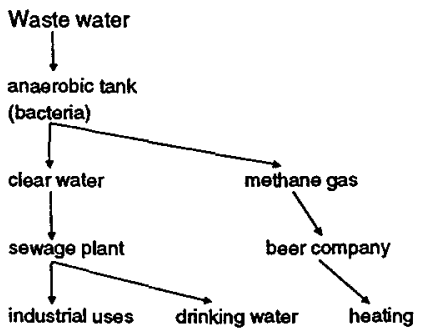

